\title{
MedienPädagogik
}

$w w w$. medienpaed.com

Zeitschrift für

Theorie und Praxis

der Medienbildung

ISSN 1424-3636

Themenheft Nr. 19: Mobile Learning in Widening Contexts: Concepts and Cases

\section{Mobile Learning with Videos in Online Communities: The example of draufhaber.tv}

Karsten D. Wolf and Klaus Rummler

\begin{abstract}
The article discusses processes of learning with user-generated video within social communities and its implementation through the online video platform daufhaber. tv. User-generated video, especially explanatory video and its organisation within online communities of practice, is seen as one of the major means of self-expression and learning of the future. Through six scenarios the article exemplifies the relevance of location and spatial orientation for learning and how this is might be used within draufhaber.tv.
\end{abstract}

\section{Introduction}

Both the use of mobile media and online video content have surged dramatically over the past decade. The penetration of mobile devices is at nearly $100 \%$ amongst adolescents and about 20 to $25 \%$ of them have smartphones with internet access. The share of mobile internet compared to the total internet usage is still very little (about $2 \%$ ) but rising by more than $100 \%$ per year. Online video is watched by more than 1 billion people worldwide, making up about $40 \%$ of all internet data traffic by the end of 2010 and about $57 \%$ in 2014, not including video content exchanged on P2P. The Cisco Visual Networking Index predicts a 39 times increase of mobile data traffic from 2009 to 2014; according to their forecast almost 66 percent of worldwide mobile data traffic will be video in 2014 (Cisco, 2010). Video has become at least as important as text on the web and mobile usage will further the dominance of video on the Internet.

Based on this premise, the "draufhaber.tv» project is an online video platform for young learners at the transition from school to vocational education. "Draufhaber» (he/she's got it; having a dab hand at something) is a German slang word for a person who can do something very well. The platform allows young learners to share resources about their interests with other people and to present their skills and their expertise from their individual perspective via user-generated videos taken with small cameras or with their mobile phones. Adolescents and young grown ups shoot and edit videos to either show their mastery of everyday skills and crafting processes (performance videos) or to explain them to others (instructional videos). Embedded tools for video editing and annotating provide users with an infrastructure to create re-mixes of peer videos to produce mashups of performance and 
instructional videos. The platform is designed to help learners to organize themselves in communities of practice and to get in touch with apprentices and young professionals in different fields of interest in order to exchange knowledge and to get insights into possible professions, trades and careers.

To re-connect these informal and de-institutionalized learning processes to formal (vocational) education, draufhaber.tv supports a teacher and expert layer for professional reflection of user-generated videos. Furthermore, video-based documentation of their everyday life's cultural practices, interests and expertise are seen as a possible bridge to the job market especially for at-risk learners. Learners may select and comment their videos to create portfolios and submit them to potential employers.

This article first describes the basic learning framework of draufhaber.tv (Section 2) as well as specific concepts of learning with video (Section 3). It then explains the contribution of mobility in the context of the project and describes six scenarios of mobile learning within draufhaber.tv. The article concludes with a positioning of mobile video communities within the mobile complex.

\section{Learning within online communities}

The phenomenon of learning within social communities on the internet can generally be conceptualised with communities of practice (CoP; Wenger, 1998). CoP are informal groups of individuals or networks with common goals and interests who communicate with each other over a longer period of time, who exchange experiences, who commonly solve problems, who collaboratively collect and build knowledge and learn from each other (Brown \& Duguid, 1991; Shaffer \& Anundsen, 1993; Wilson, 1995; Wolf, 1997). Learning within a CoP is a co-constructive and situative process (Lave \& Wenger, 1991). The primary functional goals of the online community project draufhaber.tv, therefore, are to support and nurture (following Whittaker, Isaacs, \& O'Day, 1997):

- common goals, interests, needs or activities of the members;

- repeated and active participation of the members;

- intensive interactions, strong emotional relationships and shared activities among the contributors;

- access to the shared resources with clearly defined rules of access;

- reciprocal activities like exchange of information, support and services among members;

- common rules of activity and common language;

- voluntary membership.

Sharing videos online as a «cultural space of participation» (Müller, 2009, p. 136) can be understood as collaborative production. It often means to capture glimpses, moments and personal experiences and to provide them to relevant others 
with the least technical obstacles. As David Buckingham puts it with reference to taking videos in classrooms:

Set against the tendency towards individualization, group work needs to be perceived as a matter of mutual self-interest: students need to recognize that only by pooling resources, expertise and ideas can they get the job done. (Buckingham, 2003, p. 187)

More generally Wolf (2001, p. 199) presents a hierarchical model for participative learning in online communities (5C-model, see Figure 1):

Create: a basic element of a constructivist learning environment is to allow learners to create their own contents. By creating an external representation they make parts of their internal world model explicit.

Construct: instead of accumulating unrelated bits of knowledge, students need to construct a deeper structure connecting their own and other students' representations. They should identify parallels, connections, dependencies, and conclusions as well as omissions, contradictions, or errors.

Communicate: a central functional element of teaching-learning processes is the exchange of information, knowledge, experiences, opinions and attitudes between the learners as well as between the learners and the teacher. This can happen within a conversation but it is also possible to use other media such as a text, an illustration, a physical model, or an outline - public entities in the sense of Papert (1991). As shown in Figure 1, the curved arrows symbolize that communication processes depend on an active intake instead of a passive input.

Cooperate: learning is a process highly dependent on the willingness of the interaction partners to help each other. Asking for and receiving answers, help or guidance is a central learning activity. Cooperation can also mean to take over co-responsibility for other students' learning.

Collaborate: Collaboration means that two or more persons are jointly working to solve a problem or produce some entity, shouldering the responsibility for the result together. Both success and failure will be attributed to all members involved in collaboration. 


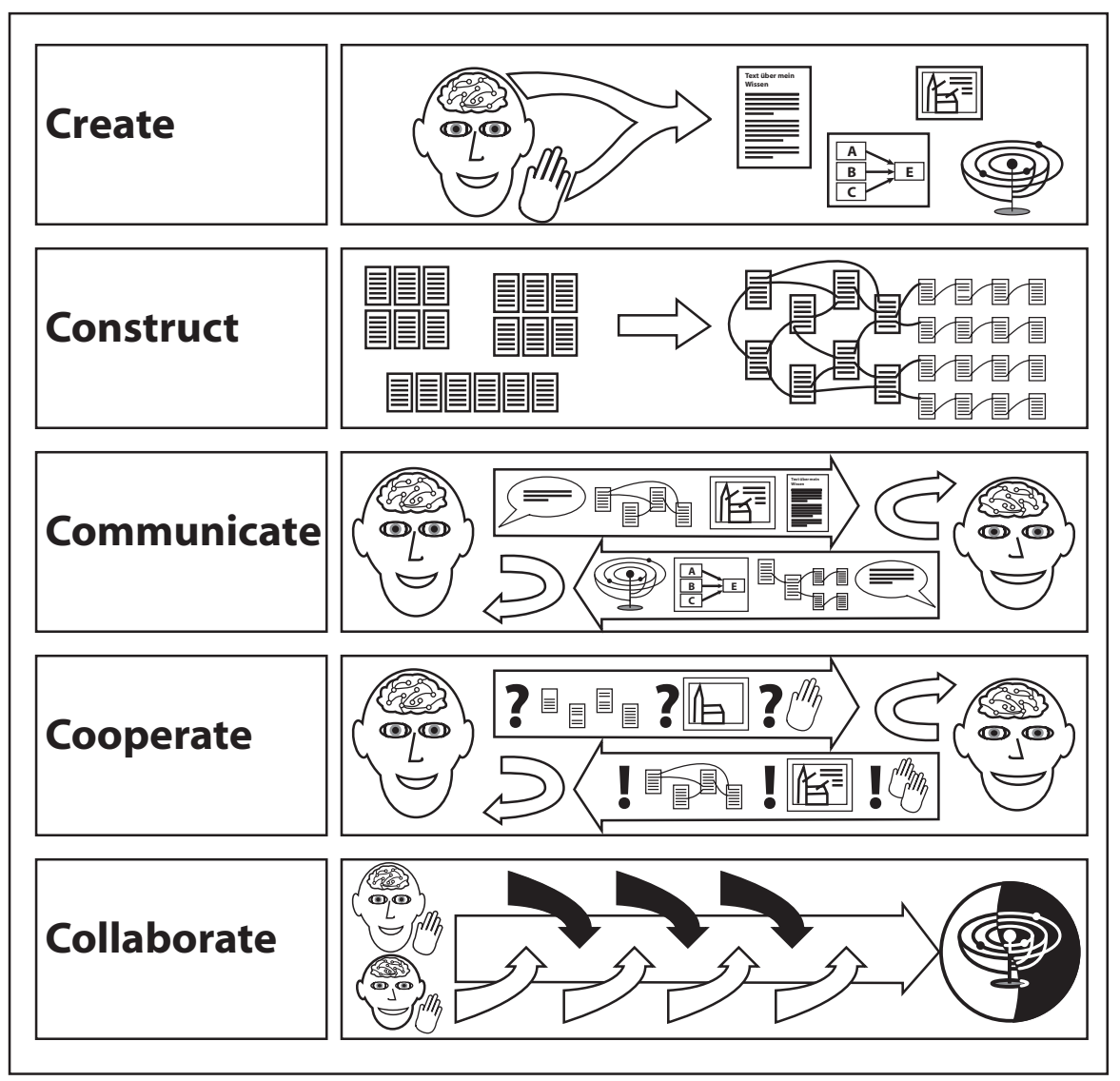

Figure 1: 5Cs of constructivist learning in groups (Wolf, 2001, p. 200)

John Seely Brown and Richard P. Adler (2008) presented a similar circular progression model that fosters «shared, distributed, reflective practicums in which experiences are collected, vetted, clustered, commented on, and tried out in new contexts» (Brown and Adler, 2008, p. 28). Practicums in their view are «places where knowledge is created and stored» and distributed that should support «a process of creating/using/re-mixing (or creating/sharing/using)» (ibid). While their concept of practicums is for the most part equivalent to Seymour Papert's idea of public entities, they explicitly add an «open knowledge exchange zone», which "provides venues for sharing experiences / evidence to improve practice» by re-mixing. 


\section{A Circle of Knowledge Building and Sharing}

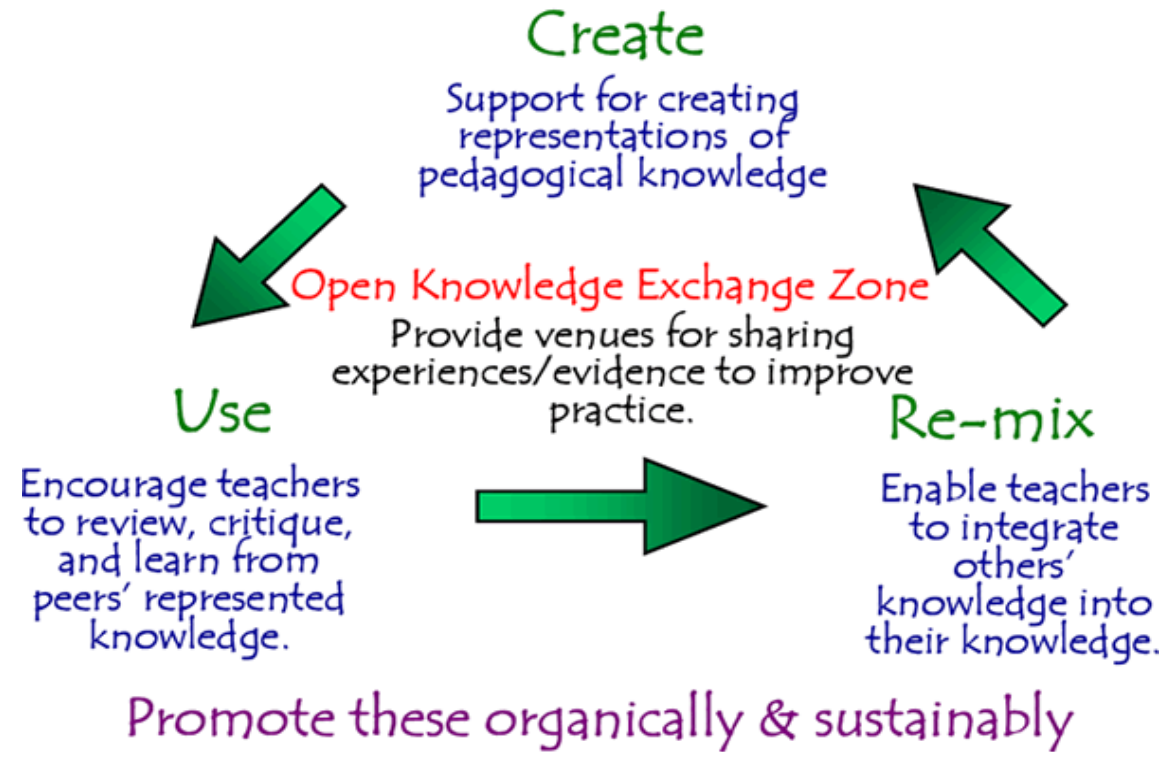

Figure 2: A Circle of Knowledge Building and Sharing (Brown \& Adler, 2008, p. 28)

Draufhaber.tv is designed as a community service which strives to create such an open exchange zone by enabling sharing of videos to emphasize participation (e.g. creating, re-mixing). From individual creation and construction to communication, cooperation and finally collaboration (or co-creation), the platform tries to engage young people in meaningful learning activities, constructive reflection and creative self-expression.

\section{Learning with user-generated video}

Informal peer-learning depends on showing each other how to do something and to give feedback on first attempts and further refinements. Video seems to be a natural fit because of its relative ease to produce and to use - at least if the video production is more or less just a recorded real time demonstration with some helpful hints.

Although learning with video and the use of video in educational settings has a long tradition, there is just little reflection on the use of on-line video platforms for learning. Existing video platforms, such as $5 \mathrm{~min}$ (http://www. $5 \mathrm{~min} . \mathrm{com}$ ), concentrate on explanatory content mostly based on simple models of learning. Videos on those platforms usually show the preparation and presentation as well as explanation of certain actions and operations. Those clips are often used as reference material. Users are expected to imitate the action by themselves in an 
auto-didactic way. The control and the feedback about the quality of the action is usually missing.

In contrast to this simplistic instructional approach it seems necessary to take a wider theoretical basis for the question about the processes and the dynamics how learner-generated videos might scaffold learning. A starting point is a hierarchy of three learning models:

1. Observational learning

2. Learning by reflection and analysis

3. Learning by designing and teaching

Observational learning is the most obvious applicable learning model for video. The learner is first watching the video, trying to follow and understand the preparation, execution and explanation of certain actions and operations. The learner then tries to imitate what he or she has seen. The learner's personal reproduction might additionally be recorded on video and uploaded onto an online platform. This is quite common on YouTube in the form of video comments. For qualitative and motivational reasons it seems crucial that a video-platform like draufhaber.tv offers the possibility to give feedback by a real audience (Buckingham, 2003, p. 187) about the production of the video itself as well as about the depicted content.

Learning by reflection and analysis seems to be highly relevant in the context of user-generated video. Explaining everyday life facts, situations and relationships through video by the learners requires reflection and analysis on various levels. Pea and Lindgren (2008, pp.9f) describe three dimensions of video analysis:

1. discourse style: formal and prompted or informal and exploratory

3. relationship to source material: insider (own video; actor) or outsider (other learner's video);

3. target outcome:

a. design: improving on some product, process or scheme, e.g. how to do something better than shown in the video;

$\beta$. synthesis/pattern finding: reach consensus on «the big picture», e.g. how to do something in general;

$\gamma$. evaluation: critiques and constructive feedback on a video;

$\delta$. analysis/interpretation: break down something into details; looking for causes.

In comparison to straight observational learning these dimensions help to scaffold reflective and analytic learning processes. 
Learning by teaching (Martin, 2007) and the concept of learning through design (Papert, 1991; Kafai, 1996) challenges traditional role models in formal educational settings. Learners learn by explanation and use the very common means of video on draufhaber.tv. The non-fugacity of the medium video in contrast to spoken language requires planning, preparation, reflection and storyboarding to explain the topic effectively. Designing an effective instructional video to explain something requires a deep and founded understanding of the topic which enhances an intensive examination of the topic to be explained. This concept is especially supported by the real audience (Buckingham, 2003, p. 187) and the possibility of inter-related video commentary dialogues where users may pose questions and may give suggestions for improvements. Taking up the perspective of teaching enables at the same time new communicative modes and acknowledges the producers as experts who are well familiar with the topic that they refer about.

\section{Mobility as a cultural structure and the relevance of location for lear- ning}

\subsection{Mobility as a cultural structure within the framework of the smobile com- plex>}

The question for learning in mobile situations, involving small and smart networked devices requires a theoretic framework with an explicit origin in Mobile Learning. Under the headline 〈Mobile Complex〉 (Pachler et al., 2010, p. 175) the London Mobile Learning Group (LMLG; www.londonmobilelearning.net) proposes a sociocultural and ecological approach to discuss the appropriation of world within the wider context of mobile technologies in the perspective of development and learning.

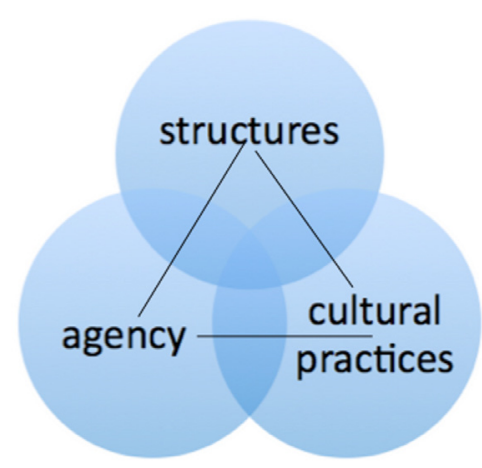

Figure 3: Socio-cultural ecology / mobile complex (Source: Pachler, Bachmair and Cook, 2010) 
The mobile complex as a theoretical and conceptual framework for mobile learning describes a triangular relationship between (a) social, cultural and technological structures; (b) cultural practices such as the assumption how learning functions in school or how informal learning functions outside school; and (c) agency, such as the learners' acting upon the world, expressing themselves, taking part in the world, achieving certain goals when using media and making meaning within convergent environments. Agency also considers the learners' identity, his/her habitus of learning and their patterns of media usage.

Following the question about user-generated video as a learning activity, the learners' knowledge building process has to rely on their expertise and on the wider complex of their agency. draufhaber.tv is designed as a centralised platform service but with strong focus on mobile accessibility. The usage of draufhaber.tv as an environment for mobile learning shows its concrete contributions and relations to the mobile complex.

\section{Relationship to technological structures:}

draufhaber.tv as an on-line platform provides the central technological structure for learning in communities and learning with video. The learners' mobile phones with built-in cameras are pre-existing structures that draufhaber.tv takes up and makes use of. Internet access for mobile phones is still not as widespread as it is needed to fluently and satisfactorily use draufhaber.tv to upload videos from mobile phones. draufhaber.tv includes location-aware and context-sensitive services. It also provides on-line video editing and re-mixing functions as technological structures which enhance the possibility for all users to equally edit and produce own material without the need for complicated and expensive software.

\section{Relationship to cultural practices:}

Sharing digital artefacts and knowledge in communities is a meaningful cultural practice of learning outside school for young people. This type of sharing includes the cultural practice of viewing, sharing and uploading on-line videos. More generally, sharing in social communities relies on the common cultural practice of learning from each other, either by seeking help from peers or by showing and telling to each other. draufhaber.tv makes use of these cultural practices in order to enhance learners' agency.

\section{Relationship to agency:}

The pedagogic intention of draufhaber.tv is the enhancement and the empowerment of the individual's agency as well as the enhancement of the distributed agency of communities. In times of user-generated content and context this means to build upon the creativity of learners, to provide environments for reflective collaboration with video and to provide an environment such as draufhaber.tv 
to support participation within a community. The empowerment of the learners' agency includes the provision and the production of videos for their own information, to help each other in solving simple tasks. More generally draufhaber.tv is also a resource for self-help in a broader holistic sense.

\subsection{Why does mobility and location matter for learning with video?}

The development of mass communication has shown an increasing ide-localisation> as we are increasingly able to bridge spatial boundaries with mobile technology, thus making our own location increasingly unimportant to access information and to communicate.

Friedrich Krotz states from the perspective of cultural and communication studies that globalisation adds to the loss of culturally homogeneous orientations and traditions in spatial neighbourhoods and thus contributes to the downfall of traditional mechanisms of social and cultural integration. (Krotz, 2007, p. 27) Adding to that, he explains and illustrates how mobile technologies and their ubiquity blur traditional spatial sites of media use, like watching television in the living room, the personal computer on the desk or the radio in the kitchen. (ibid, p. 95)

At the same time location-aware and context-sensitive services such as Gowalla, FourSquare etc. enable learners to share their geographical location and enable them to get in touch with others who are nearby or to find interesting local resources. It seems that the knowledge about one's own and others' location is a missing link to 〈re-localizes learning within the cultural structure of mobility and ubiquity. Location based services can support the learners' orientation within local and spatial structures.

Context-sensitive and location-aware mobile technologies create a need to raise the question of the relevance of spatial location for learning anew. We state that mobile video has the potential to be much more useful than desktop video for learning because it can be accessed right at the learning place. Video learning resources need to be available in practice to be useful. Mobile video unties the learner from the desktop into the action, e.g. under the engine bonnet to repair a car engine.

\subsection{Possible scenarios of mobile learning within draufhaber.tv}

Mobile and location-aware Internet technology provide a basis for ubiquitous learning infrastructures. Such infrastructures support on-site learning-by-problemsolving approaches by providing pervasive access to learning communities and re-attaching persons and knowledge to real places. Six scenarios emerge from this perspective (see also Wolf 2001, p. 214), which can be described from the draufhaber.tv project in the following schematic order: 
(a) Location-based search and documentation of learning resources:

- Search for learning resources at a place.

- Documentation of learning resources at a place.

(b) Location-based notification and monitoring

- Notification of nearby learning opportunities, resources and activities.

- Monitoring learning opportunities, resources and activities at certain places of interest.

(c) Location-based networking and summoning

- Finding nearby co-learners.

- Summoning learning advisors or experts for a place.

Scenario (a):

Location-based search and documentation of learning resources

Search: A girl and a boy are visiting a local skate park. To get an idea about the most interesting things to do, they open up draufhaber.tv on their smartphone. After searching for nearby videos, they see a map with videos taken at the park. They choose to view a couple of (360-flip» videos taken at a nearby ramp. After that, they try out the 360 -flip by themselves.

Documentation: After perfecting their 360 -flip they take a video with their mobile phone how to do a «twin 360-flips together on the ramp. The device writes the GPS location data automatically into the meta data of the video. When they upload the video to draufhaber.tv, they are being asked whether location data should be added to the video, which they accept. After having uploaded the video, their video shows up on the map next to other videos taken nearby.

Scenario (b):

Location-based notification and monitoring

Notification: A user on draufhaber.tv is a pupil in secondary education and is interested in hairstyling, doing make-up, and in street fashion. After leaving school she wants to be a hair stylist. On draufhaber.tv she is member of an uurban hair group channel and has already uploaded some videos explaining fancy hair styles for street artists. She is always interested in new learning opportunities, so she has activated the notification feature of draufhaber.tv on her smartphone. While she is visiting her cousin in another part of her hometown, the draufhaber.tv app notifies her about a couple of great shair styling tutorials> done by apprentices at two hair studios in the neighbourhood, which have been tagged as 'greats in her surban hair group. After watching the videos she decides to visit one of the hair studios to ask for an internship.

Monitoring: The above learner who is interested in hairstyling, make-up and fashion recently visited a big city near her home town and found an interesting arts and performance school. Although she won't leave school until the next 
year, she decides to monitor the school's area on draufhaber.tv for new uploads and activities. After following the activity at the school for some time, she decides to apply for the next term.

Scenario (c):

Location-based networking and summoning

Finding nearby co-learners: A young illustrator is moving to another town. He opens the draufhaber.tv app on his mobile phone and activates the notification feature of draufhaber.tv while he goes for a walk. His phone points him to an exhibition in a nearby urban youth club. While visiting the youth club, he discovers a video guide for the exhibition provided by a draufhaber.tv user who is member of the «illustrator» group. He sends a «meeting inquiry» to this group, providing some info about his interests, which is automatically sent to the local members. An hour later he receives a message with an invitation to a gallery opening this evening where he can meet two of the group members.

Summoning learning advisors or experts for a place: An apprentice for service and machinery is sent to repair a welding machine at a remote dockyard. The welding machine is a special customisation for the dockyard but the apprentice has access to the general manual for the machine only. As she cannot find any additional information to repair the machine, she visits draufhaber.tv on her tablet and starts a local search. She finds several videos, one of them gives some details about the customisation of the welding machine. She sends a connection request to the author, who is a specialist from the welding machine's manufacturer. The apprentice gets in touch with the expert via chat and with the help of the expert the apprentice is able to repair the machine.

\section{Conclusion: linking user-generated video and learning to the real world on draufhaber.tv}

draufhaber.tv is a video online community with a strong local integration. It will augment the learners' activities with information about local learning opportunities, resources and vocational structures that might be of interest to the user. By means of location awareness it will provide bridges to local industries and enterprises with the learners' digital products (videos and e-portfolios). The information displayed around and with relevance to the learners' product will be «directly relevant to the context of the learning needs and the location of the learners» (Pachler et al., 2010, p. 45).

By providing several location-based services linking people, places and contents draufhaber.tv increases the value of user-generated explanatory videos. To «relocalize' online communication it is seen as crucial that draufhaber.tv provides links to physical present local and regional structures, such as educationally-framed youth work (offene Jugendarbeit), schools which learners attend, as well as local 
enterprises as partners of the online platform who provide access to vocational education to the learners.

\section{References}

Brown, John Seely; Adler, Richard P. 2008. «Minds on Fire: Open Education, the Long Tail, and Learning 2.0.» EDUCAUSE Review 43:16-32. http://www.johnseelybrown.com/mindsonfire.pdf.

Brown, John Seely; Duguid, Paul. 1991. "Organizational learning and communities-of-practice: Toward a unified view of working, learning, and innovation.» Organization Science 2:40-57. http://www2. parc.com/ops/members/brown/ papers/orglearning.html.

Buckingham, David. 2003. Media Education: Literacy, Learning, and Contemporary Culture. Cambridge: Polity Press.

Cisco. 2010. "Cisco Visual Networking Index: Forecast and Methodology, 20092014.» http://www.cisco.com/en/US/solutions/collateral/ns341/ns525/ns537/ ns705/ns827/white_paper_c11-481360.pdf.

Kafai, Yasmin Bettina. 1996. "Learning design by making games: children's development of design strategies in the creation of a complex computational artifact.» Constructionism in Practice: Designing, Thinking and Learning in a Digital World. Ed. Yasmin Bettina Kafai and Mitchel Resnick. Mahwah, NJ: Lawrence Erlbaum Associates. 71-96.

Krotz, Friedrich. 2007. Mediatisierung: Fallstudien zum Wandel von Kommunikation. Wiesbaden: VS Verlag für Sozialwissenschaften.

Lave, Jean; Wenger, Etienne. 1991. Situated learning: Legitimate peripheral participation. Cambridge, UK: Cambridge University Press.

Madden, Mary. 2009. "The Audience for Online Video-Sharing Sites Shoots Up.» http://fe01. pewinternet.org/ /media//Files/Reports/2009/The-Audience-forOnline-Video-Sharing-Sites-Shoots-Up.pdf.

Martin, Jean-Pol. 2007. «Wissen gemeinsam konstruieren: weltweit.» Lehren und Lernen - Zeitschrift für Schule und Innovation in Baden-Württemberg 33: 29-30.

Müller, Eggo. 2009. «Where Quality Matters: Discourses on the Art of Making a YouTube Video.» The YouTube Reader, vol. 12, Mediehistoriskt Arkiv. Ed. Pelle Snickars and Patrick Vonderau. Brighton: Wallflower Press. 126-139.

Pachler, Norbert; Bachmair, Ben; Cook, John. 2010. Mobile Learning. Structures, Agency, Practices. New York: Springer. (http://dx.doi.org/10.1007/978-1-44190585-7).

Papert, Seymour. 1991. «Situating Constructionism.» Constructionism. Ed. Idit Harel and Seymour Papert. Norwood, NJ: Ablex Pub. Corp. 1-12.

Pea, Roy; Lindgren, Robb. 2008. «Video collaboratories for research and education: an analysis of collaboration design patterns.» IEEE Transactions on Lear- 
ning Technologies 4: 235-247. http://www.stanford.edu/ roypea/RoyPDF\%20 folder/A151_Pea_Lindgren_2008_IEEE-TLT.pdf.

Shaffer, Carolyn; Anundsen, Kristin. 1993. Creating Community Anywhere: Finding Support and Connection in a Fragmented World. New York: Tarcher.

Wenger, Etienne. 1998. Communities of Practice: Learning, Meaning, and Identity. New York: Cambridge University Press.

Whittaker, Steve; Isaacs, Ellen; O'Day, Vicki. 1997. «Widening the Net: Workshop Report on the Theory and Practice of Physical and Network Communities.» SIGCHI Bulletin 29: 27-30. http://bulletin.sigchi.org/1997/july/reports-1/whittaker/.

Wilson, Brent G. 1995. «What Is a Constructivist Learning Environment?.» Constructivist Learning Environments: Case Studies in Instructional Design. Ed. Brent G. Wilson. Englewood Cliffs, NJ: Prentice Hall. 3-10.

Wolf, Karsten D. 2001. «Internet based learning communities - moving from patchwork environments to ubiquitous learning infrastructures.» Multimedia Learning: Results and Perspectives. Ed. Sanne Dijkstra, David Jonassen, and Detlef Sembill. Frankfurt am Main: Peter Lang. 189-223

Wolf, Karsten D. 1997. "Lernen im Internet: Kollaboratives Lernen und Handeln.» Mediengestützte wissenschaftliche Weiterbildung: Erfahrungen und Perspektiven beruflicher Bildung und Weiterbildung. Ed. Technische Universität Braunschweig. Braunschweig: Technische Universität Braunschweig. 313-338. 